\title{
Effectiveness of Predator Control Set-up for Aquatic Pest Control in Earthen Ponds for Extensive Culture of Penaeus monodon (Fabricius, 1798)
}

\author{
Rene Geraldo Guerrero Ledesma
}

Department of Agriculture, National Fisheries Research and Development Institute, 101 Mother Ignacia Avenue, Quezon City 1103, Philippines

\begin{abstract}
A B S T R A C T
The effectiveness of a conventional predator system for tiger prawn ponds consisting of a net barrier and fence interwoven around a modified pond gateway (set-up 1) was compared to an expanded system that directed water-borne pests to a fish compartment (set-up 2). The compartment had two confinement areas holding fifty, $5 \mathrm{~g}$ sea bass fingerlings and nineteen, 300-400 g tiger grouper juveniles separated by a fine mesh net gate secured to a sluice structure. Regardless of the set-up employed, after 88 days of culture, three pest categories were identified inside the ponds: prawn predators, opportunistic feeders, and benthic scavengers. Wet biomasses of fish pests were $1.92 \mathrm{~kg}$ and $2.12 \mathrm{~kg}$, while that of mangrove snail was $29 \mathrm{~kg}$ and $80 \mathrm{~kg}$ in setups 1 and 2, respectively. Prawn length-weight frequency from 30\% biomass manifested negatively skewed population curves with the highest frequency size range of 111-120 mm: set-up 2 had a smaller skewness value $(-10.68)$ than set-up $1(-20.64)$. A significant $\mathrm{t}$-value of $-1.39\left(\mathrm{p}<0.10 ; \mathrm{df}_{18}\right.$ at $\left.\mathrm{t}_{90}\right)$ indicated that prawns raised in set-up 2 were larger than those grown under set-up 1. Finfish pests collected from set-up 2 were fewer than those in set-up 1, consisting predominantly of smaller (81-120mm) Megalops cyprinoides and Tilapia mossambicus: pests with total lengths below $81 \mathrm{~mm}$ were presumed to have been eaten by the sea bass and tiger grouper in the fish compartment. In both predator control systems, the period where tiger prawns are most vulnerable to predation pressure was during the first two months of culture, at lengths less than $111 \mathrm{~mm}$ and weights below $12.9 \mathrm{~g}$.
\end{abstract}

E-mail address: amsedelledesma.rgl@gmail.com

Received: July 15, 2019

Keywords: earthen pond, Penaeus monodon, pest,

Accepted: December 30, 2019 predator control set-up

$\mathrm{P}$ esticides have been adopted by farmers in pondbased prawn culture to eliminate predators, increase post-larval survival, and harvest yield (Bocek 2015; Clearwater et al. 2008). Tea seed applied at a rate of $200 \mathrm{mg} / \mathrm{L}$ of pond water (Clearwater et al. 2008; Terazaki et al. 1980) or niclosamide at doses not exceeding $1.0 \mathrm{mg} / \mathrm{L}$ (Napaumpaiporn et al. 2012; Calumpang 1994) are commonly used in Asia. Chemical pesticides have been limited to pond preparation due to their increasing costs. Instead, structures such as filter box screens, bamboo fences, bag nets, pond liners, and dike fortifications have been installed as cheaper alternatives. Nonetheless, albeit the number of resources invested, predators would enter ponds through leaks and cracks (Apud et al. 1983). This study investigated the effectiveness of predator control systems for $P$. monodon (tiger prawn) earthen ponds. The study site was a traditional aqua-farm practicing tiger prawn cum milkfish poly-culture (Hadie et al. 2014), encountering problems with aquatic pest infestation. Two earthen ponds with an area of $1,500 \mathrm{~m} 2$ and an average mid-pond depth of $1 \mathrm{~m}$ were selected. A bamboo fence encircled the first pond's modified gateway with a fine mesh net interwoven over it (Fig.1). This 


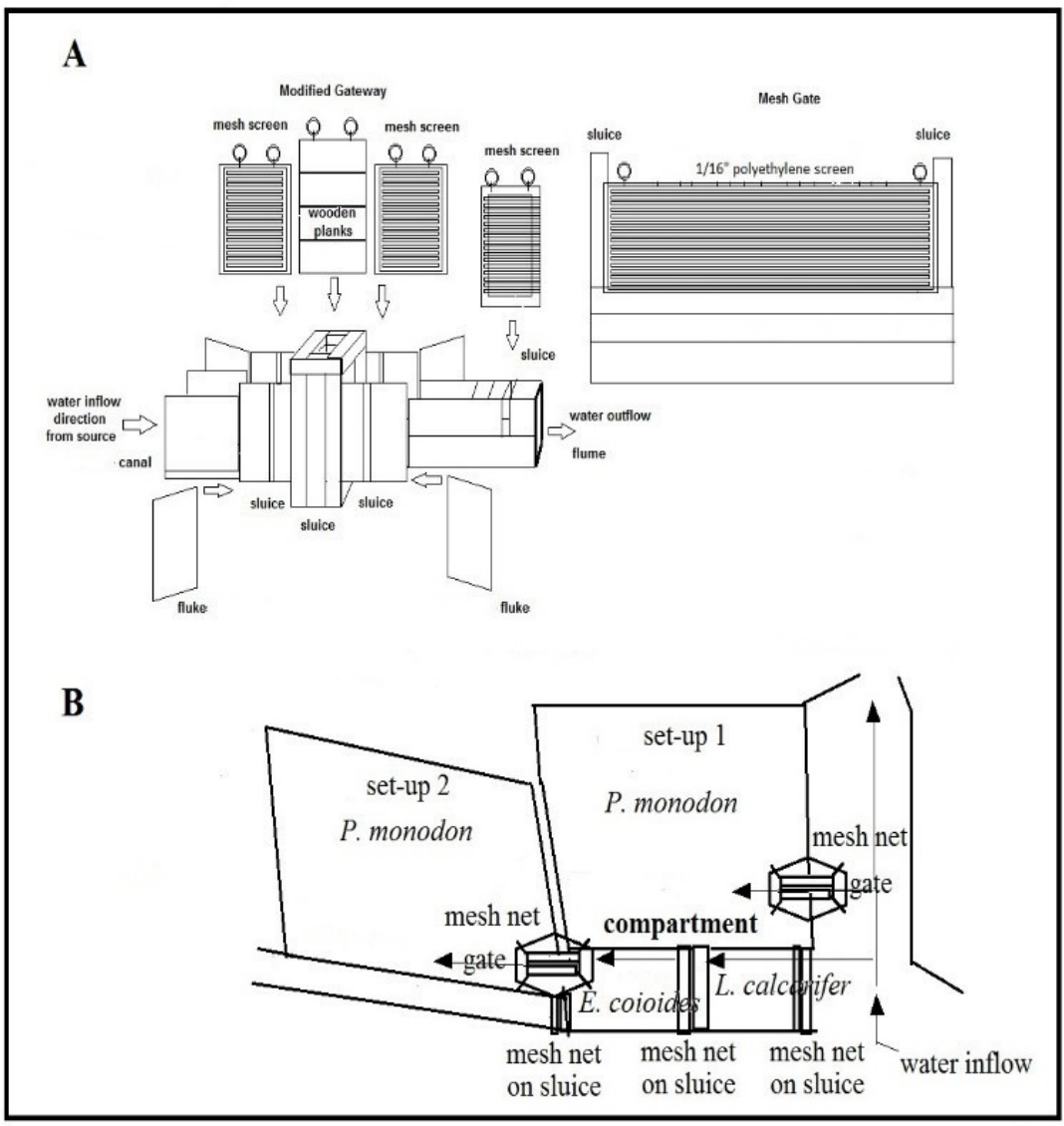

Figure 1. Components of the modified gateway, mesh gate, "biocontrol" compartment (A), and place where structures were situated in set-up 1 and 2 (B). Both set-ups used the modified gateway for pond water entry. In set-up 2, the 1/16" polyethylene screen mesh net gate (top right image) provided separation for E. coioides and L. calcarifer in the "biocontrol" compartment.

conventional predator control system was designated as predator control set-up 1. Predator control set-up 2 was termed expanded predator control system.

Other than having a modified gateway, setup 2 was also provided with a "biocontrol" compartments placed to discourage water-borne pests from entering the pond (Fig.1B). The 1/16" polyethylene screen mesh net gate separated fifty, $5 \mathrm{~g} \mathrm{~L}$. calcarifer and nineteen, 300-400 g E. coioides within the compartments. Pond preparation included pond drying, muck removal, furrowing, fertilizing, tea seed application, and water filling until the mid-depth of $1 \mathrm{~m}$ was reached.

Stage 12 post-larval $P$. monodon were obtained from a private hatchery, acclimated, and directly seeded into the ponds at 6,000 post-larvae per pond (4 post-larvae per m3). Farm-made feeds utilizing local ingredients were used wherein crude protein level was limited to $20 \%$ due to the presence of natural food (aufwuchs). Effectiveness of predator control set-up 1 versus 2 was determined by collecting the total harvest biomass and the pests. The frequencies and size ranges of prawns were compared using the one-tailed, independent T-test to determine if tiger prawns in set-up 2 were larger than those raised in set-up 1. Frequency distributions of prawns grown in the two ponds were also constructed based on size ranges of total length $(\mathrm{mm})$ derived from one-third of the prawn population. Population curves were subjected to the Skewness formula. Total length or carapace length ratios were derived to providing insight into the morphology of the prawns raised under the two set-ups.

On the 88th day of harvest, three major pest types were categorized: prawn predators (Megalops cyprinoides), opportunistic feeders/competitors (Tilapia mossambicus and Chanos chanos), and benthic mangrove snails/scavengers (Cerithidea cingulata). Mangrove snails comprised the largest pest biomass in both set-ups (Table 1). Snail biomass in set-up 2 was only $36.25 \%$ the amount of set-up 1 . In set-up 2 , prawn 
Table 1. Contribution of pests and tiger prawns to pond biomass.

\begin{tabular}{|l|r|r|r|r|}
\hline Harvested Species & \multicolumn{2}{|c|}{ Set-up 1 } & \multicolumn{2}{|c|}{ Set-up 2 } \\
\hline Finfishes & Biomass (g) & $\mathrm{g} / \mathrm{m}^{3}$ & Biomass $(\mathrm{g})$ & $\mathrm{g} / \mathrm{m}^{3}$ \\
M. cyprinoides & $2,121.50$ & 1.41 & 1,921 & 1.42 \\
T. mossambicus & 1,106 & & 1,100 & \\
C. chanos & 331.50 & & 116 & \\
Mangrove Snails & 684 & & 705 & \\
C. cingulata & 80,000 & 53.33 & 29,000 & \\
& 80,000 & & 29,000 & \\
Tiger prawn & 882 & & & \\
P. monodon & 882 & & 3,906 & \\
\hline \multicolumn{1}{r|}{ Totals } & $83,003.50$ & 55.33 & 3,906 & \\
\hline
\end{tabular}

harvest increased by as much as three-fold compared to set-up 1 (3.90 vs. $0.88 \mathrm{~kg})$.

The modal range of $111-120 \mathrm{~mm}$ had the highest prawn frequencies from samples harvested in set-up $2(28.57 \%$ at $\mathrm{n}=84)$ and $1(52.94 \%$ at $\mathrm{n}=34)(\mathrm{Ta}-$ ble 2). Population curves of prawn lengths were asymmetrical for both ponds resembling a curve leaning toward the left (Fig. 2). The negative skewness value $(-20.64)$ of set-up 1 produced a narrow curve, wherein $26.47 \%$ were situated at the larger size ranges above $120 \mathrm{~mm}$. Consequently, skewness value $(-10.68)$ of set-up 2 produced a wider curve, wherein $61.90 \%$ of prawn samples were distributed to larger size ranges of $121-170 \mathrm{~mm}$. Ninety percent $(90.47 \%)$ of prawns raised in set-up 2 weighed from 13 to 27 g per individual. In contrast, prawns from set-up 1 did not exceed $19 \mathrm{~g}$. In both ponds, prawns with lengths below 111 $\mathrm{mm}$ were scarce due to predator pressure on smaller prawns (20.59 and 9.52\% under set-ups 1 and 2, respectively).

With regard to independent $t$-test prawn frequencies for ten size ranges for length $(\mathrm{N}=10)$ at $\mathrm{p}<$ 0.10 , the calculated $t$-value $=|-1.39585|=1.39585 \mathrm{ex}-$ ceeded the tabular value $t 90=1.33$ ( $\mathrm{t} 90=1.33$ at $\mathrm{df} 18$, $\mathrm{p}$-value $=0.089871)$ indicating that prawns in set-up 2 were larger than those in set-up 1 . Total length or carapace length $(\mathrm{tl} / \mathrm{cl})$ ratios indicated that prawns from set-up 2 had a larger carapace and a shorter, well-rounded body compared to those harvested in set-up 1 ( 2.28 vs. 2.36 , respectively).

Finfish pests collected in set-up 2 were fewer than those in set-up 1 (Table 3). Slower, more sluggish T. mossam- bicus would easily fall prey to the carnivorous fish within the "biocontrol" compartment.

Megalops cyprinoides brought about significant harvest losses to both ponds regardless of the predator control set-up employed to shield the ponds against pests. The main diet of M. cyprinoides consists of live insects, copepods, and prawns (Mathew 1988; Kuthalingam 1958); after that, shifting from copepods to prawns when they reach a length of 24.6 $\mathrm{mm}$ (Kuthalingam 1958). Prawn population curves of both ponds displayed a negatively-skewed curve, with fewer smaller prawns at the left side of the modal size range as a result of predation pressure by $\mathrm{M}$. cyprinoides. Curve shape was influenced by the abundance of smaller M. cyprinoides juveniles with lengths between $41-160 \mathrm{~mm}$ (54.17 and $62.50 \%$ for set-ups 1 and 2, respectively). Prawns with short lengths $(<111$ $\mathrm{mm}$ ) and weights below $10 \mathrm{~g}$ were easily targeted by smaller M. cyprinoides, reducing their frequencies in their respective pond populations. Biomass of finfish pests that infiltrated the ponds was the same in both set-ups at $1.4 \mathrm{~g}$ of finfish per $\mathrm{m} 3$ of pond water. Installation of a "biocontrol" compartment in set-up 2 resulted in smaller $(<120 \mathrm{~mm})$ and fewer (37 in set-up 1 vs. 5 in 2) T. mossambicus that reduced grazing of natural food, resulting in a higher prawn harvest biomass of $3.9 \mathrm{~kg}$. In set-up 1, T. mossambicus and M. cyprinoides were more abundant, resulting in higher prawn predation pressure that reduced the harvest to only $0.88 \mathrm{~kg}$. In both predator control systems, the period where prawns were most vulnerable to predation pressure was during the first two months of culture at 
Table 2. Tiger prawn length and weight frequencies.

\begin{tabular}{|c|c|c|c|c|c|}
\hline \multirow[b]{2}{*}{ Group } & & \multicolumn{2}{|c|}{ Set-up 1} & \multicolumn{2}{|c|}{ Set-up 2} \\
\hline & $\begin{array}{l}\text { Range of } \\
\text { total length }\end{array}$ & prawn frequency & $\begin{array}{l}\text { average wet } \\
\text { weight }\end{array}$ & prawn frequency & $\begin{array}{l}\text { average wet } \\
\text { weight }\end{array}$ \\
\hline & $(\mathrm{mm})$ & & (g) & & (g) \\
\hline 1 & $71-80$ & 1 & 4.90 & 0 & \\
\hline 2 & $81-90$ & 4 & 6.31 & 1 & 6.97 \\
\hline 3 & $91-100$ & 2 & 7.91 & 0 & \\
\hline 4 & $101-110$ & 0 & & 7 & 10.75 \\
\hline 5 & $111-120$ & 18 & 11.65 & 24 & 12.96 \\
\hline 6 & $121-130$ & 4 & 13.79 & 22 & 15.38 \\
\hline 7 & $131-140$ & 3 & 16.13 & 21 & 18.02 \\
\hline 8 & $141-150$ & 2 & 18.64 & 7 & 20.87 \\
\hline 9 & $151-160$ & 0 & & 1 & 23.94 \\
\hline \multirow[t]{2}{*}{10} & $161-170$ & 0 & & 1 & 27.22 \\
\hline & Totals & 34 & & 84 & \\
\hline
\end{tabular}

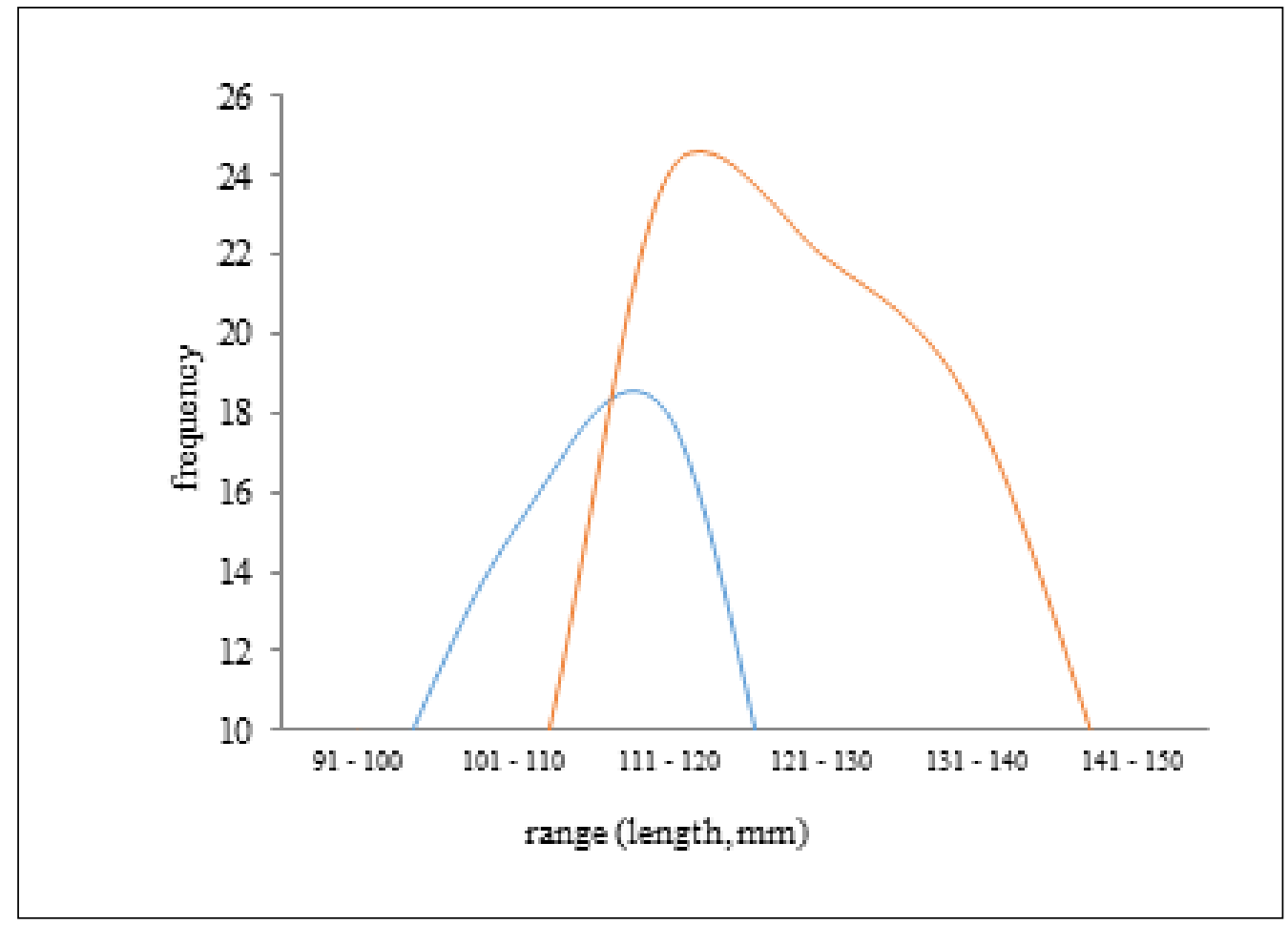

Figure 2. Asymmetrical population curves of tiger prawns in set-ups 1 (blue) and 2 (red). 
The Philippine Journal of Fisheries 26(2): 61-65

Table 3. Number and frequency of finfish predators in ponds with a predator control set-up.

\begin{tabular}{|l|l|l|l|r|r|l|l|l|r|r|}
\hline & \multicolumn{3}{|c|}{ Set-up 1 } & \multicolumn{5}{c|}{ Set-up 2 } \\
\hline $\begin{array}{l}\text { Total Length } \\
(\mathrm{mm})\end{array}$ & TM & MC & CC & Total & Percent & TM & MC & CC & Total & Percent \\
\hline $41-80$ & 24 & & & 24 & 38.10 & & 1 & & 1 & 2.38 \\
\hline $81-120$ & 11 & 3 & & 14 & 22.22 & 4 & 14 & & 18 & 42.86 \\
\hline $121-160$ & 2 & 10 & & 12 & 19.05 & 1 & 5 & & 6 & 14.29 \\
\hline $161-200$ & & 7 & & 6 & 9.52 & & 7 & & 7 & 16.67 \\
\hline $201-240$ & & 3 & & 3 & 4.76 & & 5 & & 5 & 11.90 \\
\hline $241-280$ & & 1 & 1 & 2 & 3.17 & & & 5 & 5 & 11.90 \\
\hline $281-320$ & & & 2 & 2 & 3.17 & & & & 0 & 0.00 \\
\hline & & & & & & & & & & \\
\hline Totals & 37 & 24 & 3 & 63 & 100.00 & 5 & 32 & 5 & 42 & 100.00 \\
\hline
\end{tabular}

legend: $\mathrm{TM}=\mathrm{T}$. mossambicus; $\mathrm{MC}=\mathrm{M}$. cyprinoides; $\mathrm{CC}=\mathrm{C}$. chanos

lengths less than $111 \mathrm{~mm}$ and weights below $12.9 \mathrm{~g}$.

Direct stocking of hatchery-reared prawn post-larvae into extensive prawn ponds resulted in significant losses due to predation and feed competition by aquatic pests. The extent of finfish pest infiltration was the same in both ponds at $1.4 \mathrm{~g}$ of finfish pest per cubic meter of pond water. Installation of predator control compartments with E.coioides and L. calcarifer fish serving as biocontrols, or setting up traditional fine mesh nets fronting the gate of ponds did not prevent the entry of unwanted pests.

\section{RE F E R E N C E S}

Apud FD, Torres PL Jr., Primavera JG. 1983. Farming of prawns and shrimps. (Aquaculture Extension Manual No. 5) (3rded.). Tigbauan, Iloilo Philippines: SEAFDEC Aquaculture Department.

Bocek A, editor. 2015. Eliminating unwanted fish and harmful insects from fishponds. Alabama; Auburn University International Center for Aquaculture and Aquatic Environments. 16pp.

Calumpang SMF. 1994. Fate of niclosamide in various components of a fish and prawn pond ecosystem. Phil. Agr. 77(4) pp.393-401.

Clearwater SJ, Hickey CW, Martin ML. 2008. Review of potential piscicides and molluscicides for controlling aquatic pest species in New Zealand. Science for Conservation 283. 74p.

Hadie W, Hadie LE, Rasidi. 2014. Polyculture of Tiger
Prawn (Penaeus monodon) in Low Salinity of Brackish Water Fish ponds. Proceeding of International Conference of Aquaculture Indonesia (ICAI) 2014.

Kuthalingam MDK. 1958. Studies on post larvae and feeding habits of some fishes found in the Madras plankton. J. Madras Univ. 28 B (1): 1-11 in: Noble, A. Food and feeding of the post-larvae and juveniles of Megalopscyprinoides (Brouss.). Indian Journal of Fisheries 20 (1), pp. 203-204.

Mathew AK. 1988. Studies on some aspects of biology of two estuarine fishes M. cyprinoides and Scatophagusargus. Ph.D. Thesis. Cochin University of Science and Technology Cochin 682 016 October 1988. 169pp.

Napaumpaiporn T, Limsuwan C, Chuchird N. 2012. Acute Toxicity of Niclosamide on Creeper Shell (Cerithideacingulata) and Pacific White Prawn (Litopenaeusvannamei) Post-larvae. Kasetsart University Fisheries research Bulletin 2012, Volume 36 (1).

Southeast Asian Fisheries Development Center, Aquaculture Department. 1989. Nursery ponds in prawn farming. Aqua Farm News, 7(2), 13-15.

Terazaki M, Tharnbuppa P, Nakayama Y. 1980. Eradication of predatory fishes in prawn farms by utilization of Thai tea seed. Aquaculture v. 19 issue 3, pp. 235-242. 